\title{
Impact of a COPD comprehensive case management program on hospital length of stay and readmission rates
}

This article was published in the following Dove Press journal:

International Journal of COPD

21 March 2017

Number of times this article has been viewed

\author{
Abdulmajeed Alshabanat ${ }^{\prime}$ \\ Michael C Otterstatter ${ }^{2,3}$ \\ Don D $\operatorname{Sin}^{4,5}$ \\ Jeremy Road ${ }^{5,6}$ \\ Carmen Rempel ${ }^{6}$ \\ Jane Burns ${ }^{6}$ \\ Stephan F van Eeden ${ }^{4,5}$ \\ JM FitzGerald ${ }^{5-7}$
}

\section{On behalf of the COPD Transition Team Program}

'Department of Experimental Medicine, University of British Columbia, ${ }^{2}$ British Columbia Centre for Disease Control, ${ }^{3}$ School of Population and Public Health, ${ }^{4}$ Department of Medicine, Centre for Heart Lung Innovation, St Paul's Hospital, ${ }^{5}$ Division of Respirology, Department of Medicine, ${ }^{6}$ Department of Medicine, Faculty of Medicine, Institute for Heart and Lung Health, University of British Columbia, ${ }^{7}$ Centre for Clinical Epidemiology and Evaluation, Vancouver Coastal Health Institute, Vancouver, BC, Canada

Correspondence: Abdulmajeed Alshabanat

The Lung Centre, 2775 Laurel Street, Vancouver, BC V5Z IM9, Canada Email abalshabanat@gmail.com
Background: COPD accounts for the highest rate of hospital admissions among major chronic diseases. COPD hospitalizations are associated with impaired quality of life, high health care utilization, and poor prognosis and result in an economic and a social burden that is both substantial and increasing.

Aim: The aim of this study is to determine the efficacy of a comprehensive case management program (CCMP) in reducing length of stay (LOS) and risk of hospital admissions and readmissions in patients with COPD.

Materials and methodology: We retrospectively compared outcomes across five large hospitals in Vancouver, BC, Canada, following the implementation of a systems approach to the management of COPD patients who were identified in the hospital and followed up in the community for 90 days. We compared numbers, rates, and intervals of readmission and LOS during 2 years of active program delivery compared to 1 year prior to program implementation.

Results: A total of 1,564 patients with a clinical diagnosis of COPD were identified from 2,719 hospital admissions during the 3 years of study. The disease management program reduced COPD-related hospitalizations by $30 \%$ and hospitalizations for all causes by $13.6 \%$. Similarly, the rate of readmission for all causes showed a significant decline, with hazard ratios (HRs) of 0.55 (year 1) and 0.51 (year 2) of intervention $(P<0.001$ ). In addition, patients' mean LOS (days) for COPD-related admissions declined significantly from 10.8 to $6.8(P<0.05)$.

Conclusion: A comprehensive disease management program for COPD patients, including education, case management, and follow-up, was associated with significant reduction in hospital admissions and LOS.

Keywords: COPD, CCP, admission, readmission, length of stay

\section{Introduction}

COPD is a leading cause of morbidity and mortality worldwide and the third leading cause of death in the US. COPD results in an economic and a social burden that is both substantial and increasing. ${ }^{1,2}$ A recent report from the CIHI showed that AECOPD is the number one cause of medical hospital admissions and readmissions in Canada. ${ }^{3}$ AECOPD hospitalizations are associated with an impaired HRQL, high health care utilization, and worse prognosis. ${ }^{4-6}$ Hospitalizations due to AECOPD account for the greatest portion of the economic costs for this disease. ${ }^{7-9}$ We have previously shown in an audit of the inpatient management of COPD that there were significant care gaps particularly with discharge planning and appropriate maintenance treatment in the community for these patients. ${ }^{10}$ There was also a lack of follow-up within the community and poor adherence with regard to prescribed medications. 
As a result, a special COPD case management program was implemented, consisting of teams recruited to identify, follow, and develop comprehensive care plans for all COPD patients admitted to Vancouver's main hospitals. The objective of the present study was to retrospectively analyze a cohort of COPD patients and compare outcomes during the year prior to the program (April 1, 2011, to March 31, 2012) with those during the 2 years of the program (April 1, 2012, to March 31, 2014). The specific objectives were to determine whether implementation of a CCMP for patients with COPD was associated with a reduced rate of readmission and shorter LOS for any subsequent admission and to identify potential factors contributing to unplanned readmission despite the implementation of this case management program.

\section{Materials and methodology Design and subjects}

This was a retrospective study of all COPD patients admitted to all five hospitals in Vancouver, Canada, between April 1, 2011, and March 31, 2014. Consecutive patients from each of the participating hospitals were identified by multidisciplinary case management teams, usually comprising at least one or more respiratory therapist, nurse, and a nurse practitioner. These teams were based at five hospitals, including two large academic teaching hospitals and three community hospitals. All subjects had a previous physician diagnosis of COPD; the study protocol was approved by the ethics committees of the participating hospitals and the University of British Columbia's Clinical Ethics Committee (Vancouver Coastal Health [VCHRI/VCHA], UBC CREB\# H12-00183, and Providence Health Care, UBC-PHC REB\# H11-00786). No individual consent was required by the ethic committees as this was a retrospective administrative data-based driven study.

\section{Methods}

All identified patients were followed up in the community for up to 90 days. Follow-up included visiting patients at home within a week of hospital discharge date (or phone follow-up if patient declined a home visit). Home visits aimed at clinical assessment, review of medications and inhaler technique, education, and multidisciplinary support.

We collected data related to patient demographics, dates of hospital admission, discharge, readmission, ED visits, length of hospitalization, comorbidities, most responsible doctor service, consultation services, and RIW. Patients' outcomes during the program period were compared to those during the year prior to the program being initiated (Supplementary materials).

\section{Statistical analysis}

Outcome variables

The main outcome variables were the rate of hospital readmissions for an $A E C O P D$ and the LOS during the 2-year period after program implementation (fiscal years 2012/13-2013/14) compared to the year prior to the program (fiscal year 2011/12), especially readmission rates during the 90-day follow-up window.

\section{Descriptive and inferential analysis}

All hospital visits among our patient cohort were identified from available inpatient and ED data across the five hospitals during April 2011 to March 2014. Details of descriptive and inferential analysis are provided in the Supplementary material. ${ }^{11-13}$

\section{Results}

In total, 1,564 unique individuals were identified in our dataset. These individuals contributed 2,719 admissions, $99.1 \%$ of which were from five hospitals participating in the program. Individual patients $(n=4)$ and admissions $(n=33)$ not related to these five facilities were excluded from further analyses. Overall, $54.4 \%$ of patients were male, and the average age $( \pm \mathrm{SD})$ was $72.9( \pm 12.5)$ years for males and $75.0( \pm 11.8)$ years for females. Roughly, half of patients $(49.3 \%, n=769 / 1,560)$ were readmitted at some point during the study period (all causes, inpatient only), with COPD being the primary diagnosis in $67.5 \%(n=519 / 769)$ of readmitted cases. The overall proportion of patients who were readmitted or had an ED visit was $59.6 \%(n=930 / 1,560)$. Over the 3 years of study, average age and gender ratio remained generally constant.

\section{Readmission rate}

Progressively fewer COPD patients and COPD-related admissions were observed over the 3 years of study (Table 1). The greatest decline occurred in the first year following implementation of the case management program, with $18 \%$ fewer patients and $13 \%$ fewer admissions overall compared to the year prior to the program. Moreover, in the year preceding the program, $80.7 \%$ of all admissions in the cohort were COPD related, whereas this declined to $62.8 \%$ by the second year of the program (Table 1). Similar patterns as mentioned previously were observed when inpatient and ED visits were combined (Table 2).

The proportion of patients readmitted within 90 days of their index COPD admission declined, both for all-cause readmissions (from $34.6 \%$ to $21.8 \%$ to $20.5 \%$ ) and for COPD-related readmissions (from $28.4 \%$ to $14.0 \%$ to $11.4 \%$ ). 
Table I Admission rates for the COPD cohort during selected periods before and after program implementation (inpatients only)

\begin{tabular}{|c|c|c|c|c|}
\hline Period & $\begin{array}{l}\text { Total patients } \\
\text { admitted }\end{array}$ & $\begin{array}{l}\text { Patients admitted } \\
\text { with primary dx COPD (\%) }\end{array}$ & $\begin{array}{l}\text { Total } \\
\text { admissions }\end{array}$ & $\begin{array}{l}\text { Admissions with } \\
\text { primary dx COPD (\%) }\end{array}$ \\
\hline Preprogram & 594 & 585 (98.5) & 980 & 79I (80.7) \\
\hline Program year I & 485 & $428(88.2)$ & 857 & $621(72.5)$ \\
\hline Program year 2 & 468 & 367 (78.4) & 882 & $554(62.8)$ \\
\hline
\end{tabular}

Abbreviation: $\mathrm{dx}$, diagnosis.

Indeed, the overall distributions for numbers of readmissions within 90 days were significantly different before and after implementation of the program (Figure 1), for both all-cause admissions (K-S test, $\mathrm{D}=0.14, P<0.01)$ and COPD admissions only (K-S test, $\mathrm{D}=0.16, P<0.01$ ). The most striking change was the increased proportion of patients not readmitted within 90 days, which rose from $\sim 65 \%$ prior to the program to $80 \%$ after the program (all causes).

Examining shorter follow-up windows revealed similar results. The proportion of patients readmitted for all-causes declined from preprogram through program years 1 and 2 (within 60 days: $30.2 \%$ to $18.9 \%$ to $15.7 \%$; within 30 days: $16.3 \%$ to $14.9 \%$ to $12.9 \%$ ). Rates of COPD-related readmission declined consistently across program years for a 60-day window $(26.9 \%$ to $11.4 \%$ to $8.9 \%)$ but not for a 30 -day window ( $6.5 \%$ to $3.8 \%$ to $8.2 \%)$.

\section{Readmission times and intervals}

Considering patients with at least one readmission, median time to readmission for all causes increased from 33 days for patients admitted prior to the program to 40 days for patients admitted during year 1 of the program. Similarly, median time to readmission for COPD increased from 41.5 days for patients admitted prior to the program to 55 days for patients admitted during year 1 of the program. Note some patients admitted during year 2 of the program are not included here due to incomplete follow-up ( $<1$ year) for some individuals.

\section{Regression analyses of readmission rates}

\section{All causes}

Regression modeling with recurrent events showed that readmission rates for all causes were lower among patients admitted in the years following program delivery (Figure 2) compared to patients admitted prior to program implementation (program year effect, $P<0.001$; Table 3 ). HRs for probability of readmission were 0.55 (program year 1 ) and 0.51 (program year 2) relative to the year prior to the program (Table S1). Probability of readmission increased with the number of previous admissions (HR 2.61-23.97), and there were significant differences between facilities, fiscal years, and by RIW but not by age or between males and females (Table 3; Table S1).

\section{COPD related}

Similar to all-cause admissions, readmission rates for COPD were lower among patients with an index admission during the years of program delivery (Figure 3 ) compared to patients with an index admission prior to program implementation (significant program year effect, Table 4). HRs for probability of readmission were 0.74 (program year 1 ) and 0.72 (program year 2) relative to the year prior to the program (Table S2). Probability of readmission increased substantially with the number of previous admissions (HR 3.0-39.3), and there were significant differences between fiscal years and by age and RIW but not among facilities or between males and females (Table 4 and Table S2).

\section{LOS}

LOS for COPD-related admissions declined significantly after implementation of the program, with an average stay of 10.8 days prior to the program, 8.3 days during program year 1, and 6.8 days by program year 2 (Table S3). Between preprogram and program year 2 , the change in average LOS corresponds to a $37 \%$ decrease $(P<0.05)$.

Table 2 Admission rates for the COPD cohort during selected periods before and after program implementation (inpatients and ED visits)

\begin{tabular}{|c|c|c|c|c|}
\hline Period & $\begin{array}{l}\text { Total patients } \\
\text { admitted/ED visit }\end{array}$ & $\begin{array}{l}\text { Patients with } \\
\text { primary dx COPD (\%) }\end{array}$ & $\begin{array}{l}\text { Total ED } \\
\text { visits }\end{array}$ & $\begin{array}{l}\text { ED visits with } \\
\text { primary dx COPD (\%) }\end{array}$ \\
\hline Preprogram & 597 & $586(98.2)$ & 333 & $69(20.7)$ \\
\hline Program year I & 527 & $450(85.4)$ & 562 & $126(22.4)$ \\
\hline Program year 2 & 542 & 404 (74.5) & 882 & $203(23)$ \\
\hline
\end{tabular}

Abbreviation: $\mathrm{dx}$, diagnosis. 

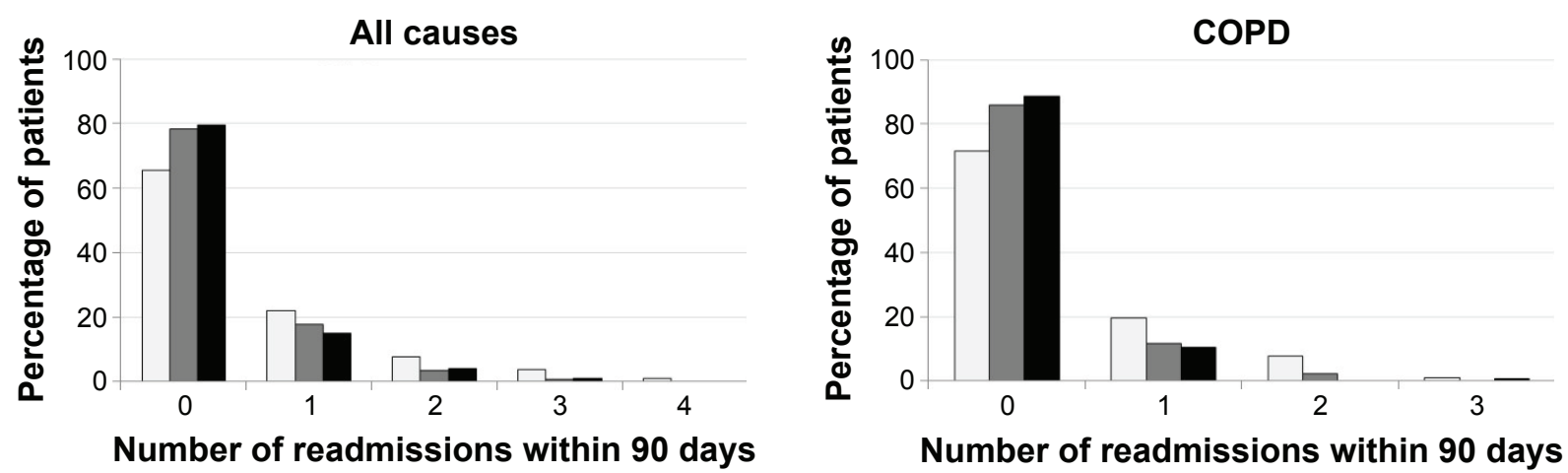

$\square$ Preprogram $\square$ Program year 1 Program year 2

Figure I Distribution of numbers of readmissions (all causes and COPD only) within 90 days for patients with an index COPD admission prior to, or during years I and 2 , of the program.

Regression modeling confirmed that the effect of the program on LOS remained significant after accounting for variation among facilities, by age, gender, and RIWs (Table 5). A similar trend was observed for all-cause admissions as well (data not shown).

\section{Discussion}

The global burden and high costs of COPD are well recognized. Hospitalizations account for more than half of COPD-related costs. ${ }^{14,15}$ Multiple studies have evaluated rehospitalization risk in COPD patients and reported that $>60 \%$ of patients were readmitted within 1 year. ${ }^{16-18}$ Unplanned readmissions have a great impact on the patient and health care costs. In our study, the unplanned readmission rate was $\sim 50 \%$ during the 3 years of study period. The program was associated with a significant decline in the rate

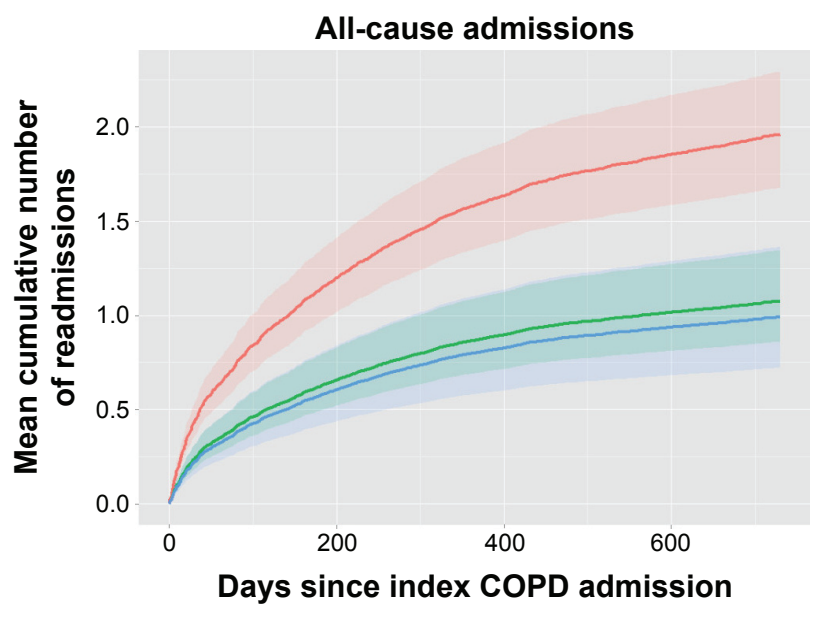

Figure 2 Mean cumulative number of all-cause readmissions relative to days since index COPD admission (inpatients only), based on Cox regression model.

Notes: Solid lines represent cohort means and colored bands represent $95 \%$ confidence intervals. Red = preprogram; green = program year I; blue = program year 2. of COPD-related hospitalizations, hospital bed days, ED visits, and most importantly the number of readmissions.

Several observational studies and RCTs of COPD interventional programs have provided inconsistent results. ${ }^{19-26}$ Our findings, however, confirm reports from previous trials of disease-specific management with comparable set of interventions and study population. ${ }^{24-26}$ In particular, it confirms the results of Bourbeau et al in a real-world setting and show that these results can be replicated across a range of health care facilities including academic and community hospitals. Bourbeau et $\mathrm{a}^{26}$ conducted an RCT in Quebec and compared the effect of a disease self-management program specific to COPD on the use of hospital services and health status among patients with moderate to severe disease. In comparison to usual care, disease-specific self-management intervention was associated with a $39.8 \%$ reduction in hospitalizations in the intervention group, as well as a $57.1 \%$ reduction in admissions for other diagnoses, a $41.0 \%$ reduction in ED visits, and a $58.9 \%$ reduction in unscheduled physician visits. Similarly, in another RCT by Rice et al, ${ }^{24}$ disease management program reduced hospitalizations for cardiac or pulmonary conditions other than COPD by $49 \%$, hospitalizations for all causes by $28 \%$, and ED visits for all causes by $27 \%(P<0.05$ for all).

Table 3 Cox regression model statistics for all-cause readmissions

\begin{tabular}{llll}
\hline Effect & df & Chi-square & P-value \\
\hline Gender & $\mathrm{I}$ & 0.034 & 0.854 \\
Facility & 4 & $27.3 \mathrm{I} 2$ & $<0.00 \mathrm{I}$ \\
Age & $\mathrm{I}$ & 3.146 & 0.076 \\
Program year & 2 & 32.830 & $<0.00 \mathrm{I}$ \\
Fiscal year & 2 & 67.356 & $<0.00 \mathrm{I}$ \\
Readmissions & 6 & $\mathrm{I}, 088.647$ & $<0.00 \mathrm{I}$ \\
Resource intensity wt & $\mathrm{I}$ & 14.765 & $<0.00 \mathrm{I}$ \\
\hline
\end{tabular}

Abbreviation: wt, weight. 


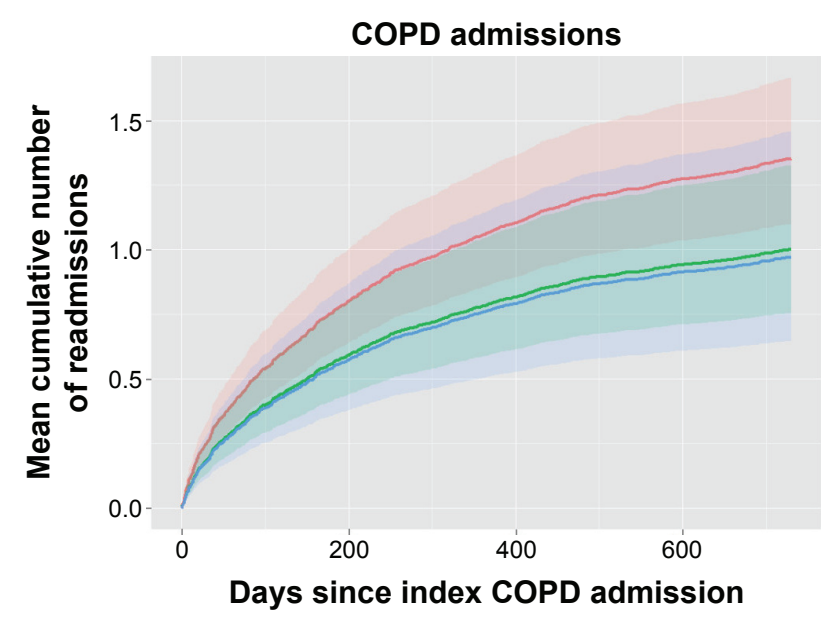

Figure 3 Mean cumulative number of readmissions with primary diagnosis of COPD relative to days since index COPD admission (inpatients only), based on Cox regression model.

Notes: Solid lines represent cohort means and colored bands represent $95 \%$ confidence intervals. Red $=$ preprogram; green $=$ program year I; blue $=$ program year 2 .

In contrast, Fan et $\mathrm{al}^{20}$ reported that a comprehensive care management program in patients with severe COPD had not decreased COPD-related hospitalizations and was associated with unanticipated higher mortality in an RCT comparing care management program with guideline-based usual care. However, limitations of the study cast some doubt on the results as it was stopped prematurely and did not include comparative scores for body mass index and exercise tolerance between the two groups.

Despite the controversy of using the 30 days readmission rate as a reflection of health care quality, ${ }^{27}$ it remains of particular importance especially in the US due to the potential financial penalties by the US CMS. We have observed a reduction in readmission rates at 30,60 , and 90 days for both all-cause and COPD-related admissions. However, our failure to show a benefit in COPD-related readmission at 30 days admissions is consistent with other studies that have shown a similar readmission rate at this time point. ${ }^{28,29}$ One potential factor is that as we reduce the LOS, there is

Table 4 Cox regression model statistics for COPD related readmissions

\begin{tabular}{llll}
\hline Effect & df & Chi-square & P-value \\
\hline Gender & I & 0.072 & 0.789 \\
Facility & 4 & 9.316 & 0.054 \\
Age & $\mathrm{I}$ & 9.683 & 0.002 \\
Program year & 2 & 6.782 & 0.034 \\
Fiscal year & 2 & 19.942 & $<0.001$ \\
Readmissions & 6 & 873.196 & $<0.001$ \\
Resource intensity wt & $\mathrm{I}$ & 10.639 & 0.001 \\
\hline
\end{tabular}

Abbreviation: wt, weight.
Table 5 Regression model statistics for length of stay analysis among inpatients with primary diagnosis of COPD

\begin{tabular}{llll}
\hline Source & df & Chi-square & P-value \\
\hline Age & $\mathrm{I}$ & 14.85 & $<0.00 \mathrm{I}$ \\
Gender & $\mathrm{I}$ & 2.55 & $0.1 \mathrm{I}$ \\
Facility & 4 & 21.85 & $<0.00 \mathrm{I}$ \\
Fiscal year & 2 & 7.60 & 0.02 \\
Resource intensity wt & $\mathrm{I}$ & 34.68 & $<0.00 \mathrm{I}$ \\
Program year & 2 & 8.25 & 0.02 \\
Gender $\times$ fiscal year & 2 & 7.37 & 0.03 \\
Resource intensity $\times$ gender & $\mathrm{I}$ & $\mathrm{I} 0.0 \mathrm{I}$ & $<0.00 \mathrm{I}$ \\
\hline Abbreviation: wt, weight. & & &
\end{tabular}

a risk of premature discharge of subjects who even with intensive community supports fail to transition to a stable clinical state at home. More importantly, the median time for COPD-related readmissions prior to the program in our study was 41.5 days, which would make examining intervention effect at longer follow-up periods more relevant.

We have previously identified significant care gaps in the management of COPD patients. ${ }^{10,30}$ Poor quality of inpatient care including inadequate discharge planning was suggested as a possible factor influencing future readmissions. ${ }^{10,30,31}$ The comprehensive program described in the current study aimed at improving the COPD health care system by filling these gaps and by developing and incorporating multiple interventions like increased disease knowledge, treatment adherence, and early follow-up and management of COPD exacerbations that have been found to be associated with improved quality of life and faster recovery, in addition to reduced hospital admissions. ${ }^{23,31-35}$

The results of this study extend the findings of previous research reporting a strong association between postdischarge care including early follow-up with lower risk of readmission. ${ }^{29,36-39}$ Sharma et $\mathrm{al}^{36}$ reported that early follow-up visits with patient's PCP significantly reduced risk of ED visits and readmissions within 30 days following acute hospitalization. A follow-up visit was associated with a protective effect against emergency readmissions in the study by Sin et al, ${ }^{37}$ which showed a $23 \%$ reduction in risk of emergency readmissions. On the other hand, lack of follow-up is a significant risk factor for early rehospitalization. ${ }^{29,38}$ Gavish et a ${ }^{38}$ reported that the lack of a follow-up visit was associated with a significant increased risk of rehospitalization within 90 days of discharge (OR, 2.91; 95\% CI, 1.06-8.01).

It is reasonable to assume that early detection and prompt treatment of an exacerbation hastens recovery and failure to seek medical attention may have consequences for both patients and the health care system. Results from several 
observational studies showed that more than one-half of COPD exacerbations were not reported to health care providers and that these had significant impact on health status. ${ }^{39,40}$ Wilkinson et $\mathrm{al}^{34}$ found that failure to report exacerbations was associated with an increased risk of hospitalization, while earlier treatment of COPD exacerbation accelerates recovery time. In addition, patients with COPD who receive adequate medical education have better quality of life and maintain significant reductions in hospitalization and ED visits. ${ }^{26}$ These findings support the results of the current study and potentiate the importance of disease-specific management programs.

We examined the role of previous hospitalization in the risk for COPD readmission. The present finding that the probability of readmission increased substantially with the number of previous hospitalizations may not be surprising as recurrent exacerbations and previous hospitalizations are associated with greater decline in lung function and higher risk for future admissions. ${ }^{16,17,41-43}$ More than any other element of COPD health care, hospitalizations account for a major portion of the economic costs for this disease. ${ }^{44,45}$ We observed changes in readmission patterns following program implementation, with fewer COPD patients and admissions overall, but proportionately more with longer readmission intervals (eg, $>90$ days) and shorter LOS. Based on these findings, it seems logical that the program could significantly improve the quality of life and reduce the high cost of hospitalization and rehospitalization in patients with advanced COPD.

Approximately two-thirds (67\%) of the admissions during the study period were COPD related. Thus, the fact that one-third of readmissions were not primarily related to COPD highlights the importance of managing patient comorbidities and identifying predictors for hospital readmission. ${ }^{17,46,47}$ In support to initial reports suggesting that the beneficial effects of disease-specific management interventions may extend beyond those related to COPD, ${ }^{17-23}$ the number of hospital readmissions was also reduced for other health problems, proving that CCMP provided better overall longterm management of COPD.

The study by Mittmann et $\mathrm{al}^{48}$ was the first study to prospectively examine the economic burden of moderate and severe COPD exacerbations from a Canadian perspective. By using data from the RUSIC study, ${ }^{49}$ they conservatively estimated the total cost of COPD exacerbations in Canada between $\$ 646$ and $\$ 736$ million a year. They also reported the average length of COPD hospitalization at 10 days with a total cost of $\sim \$ 10,000$ per stay. Our study suggests that CCMP is associated with reduction in LOS from 2.5 to 4 days (23\%-37\%). Thus, in addition to the clinical benefits of lowered LOS and readmission rates, our findings suggest that CCMP could significantly reduce costs of care of COPD patients.

\section{Limitations and reasons for efficacy}

Limitations of this study include its retrospective design with no control group/hospital, the lack of medical history and pulmonary function data as an assessment of severity, and the lack of risk factor/exposure information (eg, smoking status) for individuals. In addition, we could not evaluate the potential impact of a change in medication prescribed postintervention. We were also unable to systematically assess for mortality in the follow-up period. Despite these limitations, we feel the results are of importance and valid. The number of subjects included in the study and the duration of follow-up exceed that of any previous randomized controlled trial in this area. Our qualitative feedback from our intervention teams highlighted the presence of multiple inhalers, often containing overlapping formulations in the homes of study subjects and an associated poor level of inhaler technique. COPD patients do not easily engage in self-management programs due to many factors, ${ }^{50}$ and because of these challenges, intensive longer follow-up than in our study is required. In addition, given the known cognitive impairment and reduced levels of health literacy in this patient population, ${ }^{51,52}$ it is not hard to imagine that an intensive and sustained humanomicsbased intervention would be effective. ${ }^{53}$

\section{Conclusion}

Our study demonstrates the effectiveness of a CCMP in reducing number and length of hospitalizations, ED visits, and health care utilization in COPD patients.

\section{Abbreviations}

AECOPD, acute exacerbations of COPD; CCMP, Comprehensive Case Management Program; CMS, Centers for Medicare and Medicaid Services; CI, confidence interval; CIHI, Canadian Institute for Health Information; ED, emergency department; HR, hazard ratio; HRQL, health-related quality of life; LOS, length of stay; MR Dx COPD, primary diagnosis of COPD; OR, odds ratio; PCP, Primary Care Physician; RIW, resource intensity weight.

\section{Acknowledgments}

The abstract of this paper was presented at the Chest 2015 Annual Meeting in Montreal, Quebec, Canada, October 24-28, 2015, and the abstract published in the Chest Journal Abstracts 
Meeting. 2015;148(4_MeetingAbstracts):715A. doi:10.1378/ chest.2278816. We would like to acknowledge the members of the COPD transition team program: Carmen Rempel RRT, CRE; Jane Burns RT, CAE; Elizabeth Leonardis NP; Erin Toplak RRT, CRE; Grace Wei RN, BSN; Christine Hinds RRT, CRE; Laura Lotzer RN, MN; and Alessandria Ferraro. We also would like to express our appreciation to the COPD patients who adopted and appreciated the benefits of this program from its initiation. Funding for this program was provided through the Provincial Government Patient Focused Funding (PFF) project, BC, Vancouver, Canada.

\section{Disclosure}

The authors report no conflicts of interest in this work.

\section{References}

1. Global Initiative for Chronic Obstructive Lung Disease (GOLD) [homepage on the Internet]. From the Global Strategy for the Diagnosis, Management and Prevention of COPD. 2014. Available from: http:// www.goldcopd.org/. Accessed December 1, 2016.

2. Centers for Disease Control and Prevention. National Center for Health Statistics. National Vital Statistics Report. Deaths: Final Data for 2010 Vol. 61. Atlanta, GA: Centers for Disease Control and Prevention; 2013:118.

3. The Canadian Institute for Health Information. Top 10 Reasons for Hospitalization in Canada. 2015. Available from: https:// secure.cihi.ca/free_products/CAD_Hospitalization $\% 20$ and $\% 20$ Childbirth_Infosheet_ENrev-web.pdf. Accessed December 1, 2016.

4. Seemungal T, Donaldson G, Paul E, Bestall J, Jeffries D, Wedzicha JA. Effect of exacerbation on quality of life in patients with chronic obstructive pulmonary disease. Am J Respir Crit Care Med. 1998;157(5 pt 1): 1418-1422.

5. Mannino DM. COPD: epidemiology, prevalence, morbidity and mortality, and disease heterogeneity. Chest. 2002;121(5 suppl):121S-126S.

6. Siafakas NM, Vermeire P, Pride NB, et al. Optimal assessment and management of chronic obstructive pulmonary disease (COPD). Eur Respir J. 1995;8(8):1398-1420.

7. Strassels SA, Smith DH, Sullivan SD, Mahajan PS. The costs of treating COPD in the United States. Chest. 2001;119(2):344-352.

8. Khakban A, Sin DD, FitzGerald JM, et al. Ten-year trends in direct costs of COPD: a population-based study. Chest. 2015;148(3):640-646.

9. Miravitlles M, Murio C, Guerrero T, Gisbert R; DAFNE Study Group. Decisiones sobre Antibioticoterapia y Farmacoeconomía en la EPOC. Pharmacoeconomic evaluation of acute exacerbations of chronic bronchitis and COPD. Chest. 2002;121(5):1449-1455.

10. SandhuSK, Chu J, Yurkovich M, HarrimanD, Taraboanta C, FitzGeraldJM. Variations in the management of acute exacerbations of chronic obstructive pulmonary disease. Can Respir J. 2013;20(3):175-179.

11. Cook RJ, Lawless JF. The Statistical Analysis of Recurrent Events. Berlin: Springer Science \& Business Media; 2007.

12. McDaniel JG. Analysis of acuity trends using resource intensity weights via the CIHI portal. Adv Inform Technol Commun Health. 2009; 143:42.

13. Guo Z, Gill TM, Allore HG. Modeling repeated time-to-event health conditions with discontinuous risk intervals: an example of a longitudinal study of functional disability among older persons. Methods Inf Med. 2008;47(2):107.

14. Oostenbrink JB, Rutten-van Mölken MP. Resource use and risk factors in high-cost exacerbations of COPD. Respir Med. 2004;98:883-891.

15. Sullivan SD, Ramsey SD, Lee TA. The economic burden of COPD. Chest. 2000;117(2 suppl):5S-9S.
16. Almagro P, Barreiro B, Ochoa de Echaguen A, et al. Risk factors for hospital readmission in patients with chronic obstructive pulmonary disease. Respiration. 2006;73(3):311-317.

17. Garcia-Aymerich J, Farrero E, Félez MA, et al; Estudi del Factors de Risc d'Agudització de la MPOC investigators. Risk factors of readmission to hospital for a COPD exacerbation: a prospective study. Thorax. 2003;58(2):100-105.

18. Gudmundsson G, Gislason T, Janson C, et al. Risk factors for rehospitalisation in COPD: role of health status, anxiety and depression. Eur Respir J. 2005;26(3):414-419.

19. Ofman JJ, Badamgarav E, Henning JM, et al. Does disease management improve clinical and economic outcomes in patients with chronic diseases? A systematic review. Am J Med. 2004;117(3):182-192.

20. Fan VS, Gaziano JM, Lew R, et al. A comprehensive care management program to prevent chronic obstructive pulmonary disease hospitalizations: a randomized, controlled trial. Ann Intern Med. 2012; 156(10):673-683.

21. Zwerink M, Brusse-Keizer M, van der Valk PD. Self management for patients with chronic obstructive pulmonary disease. Cochrane Database Syst Rev. 2014;3:CD002990.

22. Watson PB, Town GI, Holbrook N, Dwan C, Toop LJ, Drennan CJ. Evaluation of a self-management plan for chronic obstructive pulmonary disease. Eur Respir J. 1997;10(6):1267-1271.

23. Casas A, Troosters T, Garcia-Aymerich J, et al. Integrated care prevents hospitalisations for exacerbations in COPD patients. Eur Respir J. 2006;28(1):123-130.

24. Rice KL, Dewan N, Bloomfield HE, et al. Disease management program for chronic obstructive pulmonary disease: a randomized controlled trial. Am J Respir Crit Care Med. 2010;182(7):890-896.

25. Rea H, McAuley S, Stewart A, et al. A chronic disease management program can reduce days in hospital for patients with chronic obstructive pulmonary disease. Intern Med J. 2004;34:608-614.

26. Bourbeau J, Julien M, Maltais F, et al. Reduction of hospital utilization in patients with chronic obstructive pulmonary disease: a disease-specific self-management intervention. Arch Intern Med. 2003;163(5):585-591.

27. Joynt KE, Jha AK. Thirty day readmission-truth and consequences. N Engl J Med. 2012;366(15):1366-1369.

28. Roberts MH, Clerisme-Beaty E, Kozma CM, Paris A, Slaton T, MapelDW. A retrospective analysis to identify predictors of COPD-related rehospitalization. BMC Pulm Med. 2016;16(1):68.

29. Jencks SF, Williams MV, Coleman EA. Rehospitalizations among patients in the medicare fee-for-service program. $N$ Engl J Med. 2009;360(14):1418-1428.

30. Bahadori K, FitzGerald JM, Levy RD, Fera T, Swiston J. Risk factors and outcomes associated with chronic obstructive pulmonary disease exacerbations requiring hospitalization. Can Respir J. 2009; 16(4):e43-e49.

31. Annandale J, Hurlin C, Lewis K. Reducing COPD admissions with a specialist chronic disease management team. Nurs Times. 2009;105(38):25.

32. Vestbo J, Anderson JA, Calverley PM, et al. Adherence to inhaled therapy, mortality and hospital admission in COPD. Thorax. 2009; 64(11):939-943.

33. Ashton CM, Kuykendall DH, Johnson ML, Wray NP, Wu L. The association between the quality of inpatient care and early readmission. Ann Intern Med. 1995;122(6):415-421.

34. Wilkinson TM, Donaldson GC, Hurst JR, Seemungal TA, Wedzicha JA. Early therapy improves outcomes of exacerbations of chronic obstructive pulmonary disease. Am J Respir Crit Care Med. 2004;169(12): 1298-1303.

35. Oancea C, Fira-Mladinescu O, Timar B, et al. Impact of medical education program on COPD patients: a cohort prospective study. Wien Klin Wochenschr. 2015;127(9-10):388-393.

36. Sharma G, Kuo Y-F, Freeman JL, Zhang DD, Goodwin JS. Outpatient follow-up visit and 30-day emergency department visit and readmission in patients hospitalized for chronic obstructive pulmonary disease. Arch Intern Med. 2010;170(18):1664-1670. 
37. Sin DD, Bell NR, Svenson LW, Man SF. The impact of follow-up physician visits on emergency readmissions for patients with asthma and chronic obstructive pulmonary disease: a population-based study. Am J Med. 2002;112(2):120-125.

38. Gavish R, Levy A, Dekel OK, Karp E, Maimon N. The association between hospital readmission and pulmonologist follow-up visits in patients with COPD. Chest. 2015;148(2):375-381.

39. Shah T, Churpek MM, Coca Perraillon M, Konetzka R. Understanding why patients with COPD get readmitted. Chest. 2015;147(5):1219-1226.

40. Langsetmo L, Platt RW, Ernst P, Bourbeau J. Underreporting exacerbation of chronic obstructive pulmonary disease in a longitudinal cohort. Am J Respir Crit Care Med. 2008;177(4):396-401.

41. Donaldson GC, Seemungal TA, Bhowmik A, Wedzicha JA. Relationship between exacerbation frequency and lung function decline in chronic obstructive pulmonary disease. Thorax. 2002;57(10):847-852.

42. McGhan R, Radcliff T, Fish R, Sutherland ER, Welsh C, Make B. Predictors of rehospitalization and death after a severe exacerbation of COPD. Chest. 2007;132(6):1748.

43. Lau AC, Yam LY, Poon E. Hospital readmission in patients with acute exacerbation of chronic obstructive pulmonary disease. Respir Med. 2001;95:876-884.

44. Miller JD, Foster T, Boulanger L, et al. Direct costs of COPD in the U.S.: an analysis of Medical Expenditure Panel Survey (MEPS) data. COPD. 2005;2(3):311-318.

45. Oostenbrink JB, Rutten-van Molken MP. Resource use and risk factors in high-cost exacerbations of COPD. Respir Med. 2004;98(9):883-891.
46. Nantsupawat T, Limsuwat C, Nugent K. Factors affecting chronic obstructive pulmonary disease early rehospitalization. Chron Respir Dis. 2012;9(2):93-98.

47. Papaioannou AI, Bartziokas K, Tsikrika S, et al. The impact of depressive symptoms on recovery and outcome of hospitalised COPD exacerbations. Eur Respir J. 2013;41(4):815-823.

48. Mittmann N, Kuramoto L, Seung SJ, Haddon JM, Bradley-Kennedy C, Fitzgerald JM. The cost of moderate and severe COPD exacerbations to the Canadian healthcare system. Respir Med. 2008;102(3):413-421.

49. FitzGerald JM, Haddon JM, Bradly-Kennedy C, Kuramoto L, Ford GT; RUSIC Study Group. Resource Use Study in COPD (RUSIC): a prospective study to quantify the effects of COPD exacerbations on health care resource use among COPD patients. Can Respir J. 2007; 14(3):145-152.

50. Korpershoek Y, Bos-Touwen I, de Man-van Ginkel J, Lammers J-W, Schuurmans M, Trappenburg J. Determinants of activation for selfmanagement in patients with COPD. Int J Chron Obstruct Pulmon Dis. 2016;11:1757-1766.

51. Villeneuve S, Pepin V, Rahayel S, et al. Mild cognitive impairment in moderate to severe COPD. Chest. 2012;142(6):1516-1523.

52. Chang SS, Chen S, McAvay GJ, Tinetti ME. Effect of co-existing chronic obstructive pulmonary disease and cognitive impairment on health outcomes in older adults. J Am Geriatr Soc. 2012;60(10):1839-1846.

53. FitzGerald J, Poureslami I. The need for humanomics in the era of genomics and the challenge of chronic disease management. Chest. 2014;146(1):10-12. 


\section{Supplementary materials Descriptive analysis}

All hospital visits among our patient cohort were identified from available inpatient and emergency department (ED) data across the five hospitals during April 2011 to March 2014. Given the need for multidisciplinary teams to be recruited, the case management program was not implemented at the same time in all facilities (start dates varied between September 2011 and February 2012), we identified for each hospital a "preprogram" period and matched "program year 1" and "program year 2" periods of equal length. For a facility beginning program delivery on February 1, 2012, for example, the preprogram, year 1 , and year 2 periods were defined as April 2011 to January 2012, April 2012 to January 2013, and April 2013 to January 2014, respectively. In this way, each period for a facility was comparable both in terms of duration and time of the year. These three periods were used to calculate and compare basic descriptive statistics on the numbers and proportions of patients and admissions and on the lengths of stay, before, and after implementation of the program. Our analyses focus on inpatient admissions with a primary diagnosis of COPD (ICD-10 codes J440, J441, J448, and J449), although we also considered patterns for "all-cause admissions" as well as in ED visits where discharge diagnosis contained the phrase "chronic obstructive".

\section{Inferential analysis}

Recurrent events regression modeling was used to assess changes in readmission rates in relation to the program. ${ }^{1}$ For this analysis, each patient's earliest hospital admission for COPD in our dataset was used as the starting point (time $=0$ ) or "index admission", for tracking through the entire study period. Time-at-risk (days) was accumulated for each patient using their discharge-to-readmission intervals (ie, not including duration of hospital stays) starting from the discharge date of their index admission. The final at-risk interval for each individual runs from their last documented discharge to end of study (March 31, 2014), with individuals being censored after their last discharge. Time-at-risk was calculated both for all-cause readmissions and for readmissions with a primary diagnosis of COPD only. The model analyzed the readmission rates for patients according to their index admission (before program implementation, during year 1 of program delivery, or beyond year 1) and included as covariates gender, hospital, age, number of previous readmissions $(1,2,3,4,5$, and $>5)$, fiscal year, and resource intensity weight (RIW, a relative measure of a patient's total resource use, used here as a proxy for severity of illness). ${ }^{2}$ This "counting process" model, an extension of the Cox regression model, estimates hazard ratios (HR) and cumulative mean readmissions by index COPD period adjusted for covariates. ${ }^{3}$ Standard errors were calculated using the robust sandwich variance estimator to account for the nonindependence of multiple readmissions by a single individual. Linear regression modeling was used to compare average length of stay (LOS) for COPD readmissions in relation to the program. Log-transformed LOS was regressed against covariates age, gender, hospital, RIW, and fiscal year, and the best-fit model was selected using backward stepwise elimination of nonsignificant interaction terms. The nonindependence of observations on individuals was accounted for using generalized estimating equations (GEE) model fitting.

\section{Intervention}

Home visit aimed at assessing patients' vitals, symptoms, review of medications, inhaler technique, immunization status, review of self-management information including deep breathing, relaxation exercises, effective cough technique, and smoking cessation counseling. Moreover, patients were also provided with teaching sessions regarding COPD management with emphasis on early detection of a flare up and encouragement to discuss with their family physician and to obtain prescriptions for antibiotics and prednisone. Written information was provided in patient's language (when available). If no written plan and/or prescriptions had been previously provided by the family physician, the patient encouraged to make appointment and discuss with family physician an alternate plan of action for future exacerbations. Support and education for family members, caregivers, facility, and home support care staff were also provided.

COPD teams proactively informed primary care physicians via faxed letter (usual) or phone call (if more urgent matter), regarding the disposition of their patients, respiratory status, and any outstanding issues from home visit, and provided with suggestions for treatment or changes to treatment based on COPD guidelines including referral for outpatient spirometry if it had not been done previously or if it needed repeating, as well as referral for pulmonary rehabilitation or specialist respiratory consultations if indicated.

Community support services were provided if ongoing chronic disease management needed beyond 3 months (respiratory therapy, physiotherapy, occupational therapy, social worker, home support, meal delivery service, etc.). After discharge from formal follow-up in program, patient encouraged to contact team for any future questions or issues. 
Table SI Parameter estimates from Cox regression model for all-cause readmissions

\begin{tabular}{|c|c|c|c|c|c|}
\hline Parameter & Estimate & SE & Chi-square & $P$-value & Hazard ratio \\
\hline Gender male & -0.011 & 0.061 & 0.034 & 0.854 & 0.989 \\
\hline Facility A & -0.092 & 0.077 & 1.436 & 0.231 & 0.912 \\
\hline Facility B & -0.250 & 0.094 & 7.009 & 0.008 & 0.779 \\
\hline Facility C & $-0.17 \mid$ & 0.078 & 4.788 & 0.029 & 0.843 \\
\hline Facility D & 0.152 & 0.075 & 4.131 & 0.042 & 1.164 \\
\hline Age & -0.005 & 0.003 & 3.146 & 0.076 & 0.995 \\
\hline Program year I & -0.602 & 0.105 & 32.809 & $<0.00$ I & 0.548 \\
\hline Program year 2 & -0.683 & 0.154 & $19.57 \mid$ & $<0.001$ & 0.505 \\
\hline Fiscal year $2012 / 13$ & 0.842 & 0.108 & 61.296 & $<0.001$ & 2.321 \\
\hline Fiscal year $2013 / 14$ & 1.095 & 0.148 & 54.791 & $<0.001$ & 2.988 \\
\hline Readmissions $=1$ & 0.962 & 0.068 & 202.381 & $<0.001$ & 2.617 \\
\hline Readmissions $=2$ & 1.451 & 0.090 & 258.780 & $<0.001$ & 4.269 \\
\hline Readmissions $=3$ & 2.130 & 0.111 & 371.394 & $<0.001$ & 8.417 \\
\hline Readmissions $=4$ & 2.088 & 0.131 & 254.700 & $<0.00$ I & 8.072 \\
\hline Readmissions $=5$ & 2.563 & 0.165 & 240.134 & $<0.001$ & 12.976 \\
\hline Readmissions $>5$ & 3.177 & 0.136 & 542.089 & $<0.001$ & 23.974 \\
\hline Resource intensity wt & -0.089 & 0.023 & 14.765 & 0.000 & 0.915 \\
\hline
\end{tabular}

Notes: Estimates and hazard ratios relative to reference categories for gender (females), facilities (reference hospital), index COPD fiscal year (preprogram), fiscal year (20II/I2), and number of readmissions (0).

Abbreviations: SE, standard error; wt, weight.

Table S2 Parameter estimates and hazard ratios from Cox regression model for MR Dx COPD readmissions

\begin{tabular}{|c|c|c|c|c|c|}
\hline Parameter & Estimate & SE & Chi-square & $P$-value & Hazard ratio \\
\hline Gender male & 0.022 & 0.082 & 0.072 & 0.789 & 1.022 \\
\hline Facility A & -0.195 & 0.099 & 3.869 & 0.049 & 0.823 \\
\hline Facility B & -0.249 & 0.119 & 4.350 & 0.037 & 0.780 \\
\hline Facility C & -0.173 & 0.104 & $2.74 I$ & 0.098 & $0.84 I$ \\
\hline Facility D & -0.004 & 0.107 & 0.002 & 0.968 & 0.996 \\
\hline Age & -0.010 & 0.003 & 9.683 & 0.002 & 0.990 \\
\hline Program year I & -0.301 & 0.116 & 6.766 & 0.009 & 0.740 \\
\hline Program year 2 & -0.332 & 0.184 & 3.253 & $0.07 \mid$ & 0.717 \\
\hline Fiscal year $2012 / 13$ & 0.546 & 0.129 & 17.892 & $<0.001$ & 1.727 \\
\hline Fiscal year $2013 / 14$ & 0.721 & 0.187 & 14.808 & $<0.00 \mathrm{I}$ & 2.056 \\
\hline Readmissions $=\mathrm{I}$ & 1.095 & 0.087 & 158.958 & $<0.001$ & 2.989 \\
\hline Readmissions $=2$ & 1.809 & 0.121 & 222.215 & $<0.00 \mathrm{I}$ & 6.105 \\
\hline Readmissions $=3$ & 2.310 & 0.150 & 238.241 & $<0.001$ & 10.079 \\
\hline Readmissions $=4$ & 2.299 & 0.192 & 143.789 & $<0.00 \mathrm{I}$ & 9.966 \\
\hline Readmissions $=5$ & 3.046 & 0.225 & 183.508 & $<0.00 \mathrm{I}$ & 21.026 \\
\hline Readmissions $>5$ & 3.671 & 0.248 & 218.270 & $<0.00 \mathrm{I}$ & 39.279 \\
\hline Resource intensity wt & -0.112 & 0.034 & 10.639 & 0.001 & 0.894 \\
\hline
\end{tabular}

Notes: Estimates and hazard ratios relative to reference categories for gender (females), facilities (reference facility), index COPD fiscal year (preprogram), fiscal year (20I I/I2), and number of readmissions (0).

Abbreviations: SE, standard error; wt, weight; MR Dx COPD, primary diagnosis of COPD.

Table S3 Mean LOS in days among inpatients with primary diagnosis of COPD during selected periods before and after program implementation

\begin{tabular}{lll}
\hline Program & $\mathbf{n}$ & LOS $(95 \%$ CI $)$ \\
\hline Preprogram & 85 & $10.8 I^{\mathrm{a}}(7.3 \mathrm{I}-14.3 \mathrm{I})$ \\
Program year I & $\mathrm{II}$ & $8.32^{\mathrm{a}}(6.67-9.97)$ \\
Program year 2 & 190 & $6.80^{\mathrm{b}}(5.56-8.03)$ \\
\hline
\end{tabular}

Notes: Letters indicate significant differences between program years at $P<0.05$;

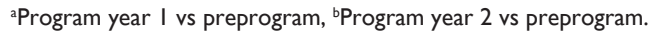

Abbreviations: $\mathrm{Cl}$, confidence interval; LOS, length of stay.

\section{References}

1. Cook RJ, Lawless JF. The Statistical Analysis of Recurrent Events. Berlin: Springer Science \& Business Media; 2007.

2. McDaniel JG. Analysis of acuity trends using resource intensity weights via the CIHI portal. Adv Inform Technol Commun Health. 2009; $143: 42$

3. Guo Z, Gill TM, Allore HG. Modeling repeated time-to-event health conditions with discontinuous risk intervals: an example of a longitudinal study of functional disability among older persons. Methods Inf Med. 2008;47(2):107. 
International Journal of COPD

\section{Publish your work in this journal}

The International Journal of COPD is an international, peer-reviewed journal of therapeutics and pharmacology focusing on concise rapid reporting of clinical studies and reviews in COPD. Special focus is given to the pathophysiological processes underlying the disease, intervention programs, patient focused education, and self management protocols.

This journal is indexed on PubMed Central, MedLine and CAS. The manuscript management system is completely online and includes a very quick and fair peer-review system, which is all easy to use. Visit http://www.dovepress.com/testimonials.php to read real quotes from published authors 